116

Notre Dame Journal of Formal Logic

Volume XVI, Number 1, January 1975

NDJFAM

\title{
PRIOR'S CRITICISM OF THE BARCAN FORMULA
}

\author{
TOBIAS CHAPMAN
}

Douglas Lackey ${ }^{1}$ agrees with Massey's conclusion that A. N. Prior is incorrect in his criticism of the Barcan formula but disagrees with him as to the source of the mistake. Prior's criticism, according to Lackey, depends on reading the existential quantifier exclusively as tensed. But we cannot do this: (a) even in ordinary speech we often require a tenseless interpretation of the quantifier; (b) in a logic containing both quantifiers and tense-operators we must have a means of distinguishing tensed from tenseless usages of the former; hence we need a present-tense operator $(J)$. I agree with Lackey's remarks but (as I shall try to show) this does not resolve the relevant difficulties. To be sure, if a logic lacks a presenttense operator but is tensed, then expressions for propositions lacking any tense-operator (i.e., $p, q, \Sigma x Q x$ etc.) will have to be read as present-tensed, and Prior's logics are normally set up in this way. This does not mean, however, that he cannot allow for a tenseless reading of the quantifier where this is necessary, e.g., Lackey's example "Jones is dead" could simply be written (where $S$ means "is named 'Jones"' and assuming that proper names are used only once to name particular individuals), "KP $\Sigma x S x N \Sigma x S x$ "; and, in general, tenseless existence could be expressed by, " $K K \Sigma x \ldots P \Sigma x \ldots F \Sigma x$ " on Prior's view that timeless existence and sempiternal existence come to the same thing (or, at least, that the one entails the other). Alternatively, if the latter view is rejected, one could simply introduce an operator indicating tenselessness. In either case Prior's criticism of the Barcan formula would remain unaffected.

The real difficulty with Prior's criticism hinges, I think, on his definitions of " $M$ " (it is possible that) and " $L$ " (it is necessary that): " $M p$ " he defines as "it either is or has been or will be the case that $p$ ", and " $L p$ " as "it is always true that $p$ ". The Barcan formula, $C M \Sigma x \phi x \Sigma x M \phi x$, he translates as "if it either is or has been or will be the case that something $\phi s$, then there is something which either $\phi s$ or has $\phi$ ed or will $\phi . "$ His criticism of it is simply this: suppose, for example, that in fact someone will fly to the moon someday but not anyone who now exists. ${ }^{2}$ Clearly this criticism does apply to the formula on the ordinary English translation that Prior gives to it, and equally clearly does not apply where the quantifiers 
are interpreted as tenseless and the $M$ in the usual way (as expressing logical possibility). The important question is whether the formula is false, not on this or on the explicit English translation that Prior gives to it, but on the interpretation he must give to it in light of the special sense that he gives to $M$.

Where the " $t \mathrm{~s}$ " stand for times Prior's $M$ can be stated: $\Sigma t . \ldots t \ldots$; so the Barcan formula can be written: $C \Sigma t \Sigma x \phi x t \Sigma x \Sigma t \phi x t$. This admits of at least three interpretations depending on whether the quantifiers are read as tensed, tenseless or a mixture of both. I will argue that it is doubtful whether Prior's criticisms stand on any of these interpretations. (1) The attempt to read all the quantifiers as tensed would render the formula incoherent since the " $\Sigma t$ " must be read as tenseless: it would be absurd to suppose that there now exists a time could be true in a respect which would allow that at some other time the time in question might not exist, at least on the natural presupposition that the " $t \mathrm{~s}$ " refer to instants and moments per $s e$ in a time series. Of course the " $t s$ " might be interpreted as special types of descriptions really referring to events (counting the existence of a "particular" as an event). " $\Sigma t \Sigma x \phi t$ "' could then be taken as meaning, "There exists an event (the one defining the temporal interval in question) which is simultaneous with the event of an $x$ ing" and here both quantifiers could be read as tensed (although they would not have to be read in that way). The difficulty with this in regard to Prior's criticism is that it would make the antecedant and the consequent in the Barcan formula equivalent in sense; so the formula certainly would not be false. (2) Similarly if all the quantifiers are read as tenseless then both the antecedant and the consequent mean: "There exists an $x$ and a time such that $x \phi$ s at that time" and the formula is true. (3) It might be justly claimed that (1) and (2) miss the point, that whether the quantifier is read as tensed or as tenseless depends on the type of individual being quantified over, ${ }^{3}$ in which case " $\Sigma t$ " should be read as tenseless and " $\Sigma x$ " as tensed. The quantifiers undoubtedly could be read in this way. (Fortunately the difficult problem of whether they should be read in this way need not concern us here.) In any case this reading does not necessarily render the Barcan formula false for its most natural interpretation would then be: There exists a time (or times) at which a presently existing thing $\phi$ s implies that there exists now something such that at some time or other it $\phi \mathrm{s}$. And this is true. Prior, of course, wants us to read the formula in the following way. The antecedant means: There exists a time such that there exists an $x$ at that time which $\phi \mathrm{s}$, and the consequent as, there now exists an $x$ such that at some time or other it $\phi s$; and on this translation the formula is false. But we cannot allow the quantifiers to make this kind of difference for it would make the first occurrence of $\Sigma x$ tenseless since " $\Sigma t \Sigma x \phi t$ " would mean, in effect, "a $\phi \mathrm{er}$ exists at some past, present or future time" (i.e., it would be tenseless in Prior's sense, not in every possible sense); whereas the second $\Sigma x$ is read as tensed. Hence even if the tenselessness, or lack of it, of a quantifier is relative to the type of object it ranges over this interpretation of the Barcan formula is just inconsistent: it would turn out to be equivocal, not false. It is worth noting that to give the order of the quantifiers the signifi- 
cance that Prior tacitly attaches to it is logically equivalent to introducing a present-tense operator. If we write it in then we have: $C \Sigma t \Sigma x \phi x t J \Sigma x \Sigma t \phi x t$ which is false but not because of the order of the quantifiers and in any case is not the Barcan formula on any interpretation.

However, I think that Prior clearly has a point here about logic and time which is obscured by his definitions of $M$ and $L$. For reasons I cannot go into here I think that Prior's convention of treating temporally unmodified propositional expressions as presently tensed is the best one. If we then introduce an operator, " $Q$ " (meaning roughly, it is open to causal influence that, or it is causally indeterminate that ${ }^{4}$ ) and retain Prior's $F$ and $P$ then formulae similar to the Barcan formula will come out false, e.g., $C Q F \sum x \phi x \sum x Q F \phi x$ and $C \sum x \phi x Q F \sum x \phi x$. I take it that this is Prior's point. 5

\section{NOTES}

1. Douglas Lackey, "Massey on tense and special relatively," Nô̂s, Vol. V (1971), pp. 419-421. Lackey is presumably right that Special Relativity does not preclude the inference of $K P q P p$ from the truth of $P q$ and that of $P p$ where $p$ and $q$ are not spatially connected. Prior's logics might be construed as unscientific were they thought to presuppose that events are absolutely past, present or future.

2. A. N. Prior, Time and Modality, Clarendon Press, Oxford (1957), p. 26.

3. This suggestion is due to Professor G. E. M. Anscombe.

4. The use of this operator is not unscientific providing that it is recognized that (a) it attaches only to propositions which describe events in the absolute future relative to some frame of reference and (b) that it will not necessarily attach to propositions describing the same events relative to some other frame or reference.

5. Historical Note: Aristotle certainly allows 'always the case' as one definition of 'necessary'. It is not so clear I think that the mediaevals allowed this definition in application to propositions. Certainly Aquinas (in Summa Theologiae, 1a. 14, 15 , Reply to Objection 3) explicitly rejects the thesis that $P p, p$ and $F p$ are different expressions of the same proposition, but he claims that certain past-tensed propositions and certain propositions which express knowledge are necessary (Summa Theologiae, 1a, 14, 13) and these need not be true for all time. Aquinas accepts the definition as giving the sense of "necessary" in application to some beings.

Aquinas does say, for instance, that the proposition "God knew that this is going to happen" is "absolutely necessary" because it is eternal. It is significant however that he used the word "eternal" not "sempiternal" implying that it is not the proposition's truth at all times that makes it necessary, but rather that the passage of time, or what happens "in" time is not relevant to its truth-value at all. Also Aquinas adds that the proposition is necessary because "significatum ut praeteritum" which could be rendered as "it is expressed as if it had taken place". In other words the proposition can be called "necessary" because it looks as if it expresses a truth about the past (although it is necessary really because it expresses a timeless truth). Thus it is not clear that Prior's use of "proposition", "necessary" and "possible" is mediaeval. 